\title{
MODIFICATION IN BRAKE LINER PROCESSING TO ENHANCE PRODUCTIVITY
}

\author{
Mahaveer Jaiswal ${ }^{1}$, Heramb Karlekar ${ }^{2}$, Abhijeet Gade ${ }^{3}$, Vinit Narvekar ${ }^{4}$, Mahesh Kale ${ }^{5}$ \\ ${ }^{1}$ Mechanical Department, VPM's MPCOE Velneshwar, Mumbai University \\ ${ }^{2}$ Mechanical Department, VPM's MPCOE Velneshwar, Mumbai University \\ ${ }^{3}$ Mechanical Department, VPM's MPCOE Velneshwar, Mumbai University \\ ${ }^{4}$ Mechanical Department, VPM's MPCOE Velneshwar, Mumbai University \\ ${ }^{5}$ Mechanical Department, VPM's MPCOE Velneshwar, Mumbai University
}

\begin{abstract}
Brake liners are composed of relatively soft but tough and heat resistance material with a high coefficient of dynamic friction typically mounted on a solid metal backing using high temperature adhesives or rivets. Before using brake liner in assembly it is needed to get finished the excess material on liner plate. Industry named "PETHE BRAKE MOTORS PRIVATE LIMITED", uses two tools to finish excess material(asbestos lining) from 2 sides of liner plate which requires double tool setting time and results in increased process time. Here, in this project we are going to modify the tool in such a way that, excess time required for resetting of tool will be reduced and production rate will be increased without disturbing any other process parameter
\end{abstract}

Keywords - Liner plate, asbestos lining, finishing tool, process time $* * *$

\section{INTRODUCTION}

\subsection{About Industry}

"PETHE BRAKE MOTORS PRIVATE LTD" is a private industry which was established and leaded by Mr. Amar Pethe in 1982. There aim is to provide good quality products with effective cost. Now Pethe Brakes come long way about 50 years. They have experience as well as outstanding industry knowledge and extensive application in this field. Today PBMPL work at 15000 sq. feet with 67 people at Guhagar. The products which this industry manufactures are spring loaded electrically released brakes, electrically released brakes, electrohydraulic thrustors. These brakes are used in escalator, tower cranes and in machines where frequent ON/OFF is required.

\subsection{Problem Definition}

Since the brake lining is applied on both sides of plate it requires excess time to get both sides finished. In addition to finishing time it takes time to change the tool, to get other side finished too.

\subsection{Objectives}

1) To reduced tool changing time or tool resetting time,

2) To increased production rate.

\subsection{Scope of Project}

Will be used in Pethe Brake Motors Private Limited for

1. Increasing production rate and

2. Decreasing processing time.

\section{EXISTING PROCESSING}

Initially casted circular liner plate along with squares hole to fixed on fixture shown below is finished as per the thickness of lining material on $\mathrm{CNC}$ machine. On finished area Anabond binder is applied on which lining material is fixed.

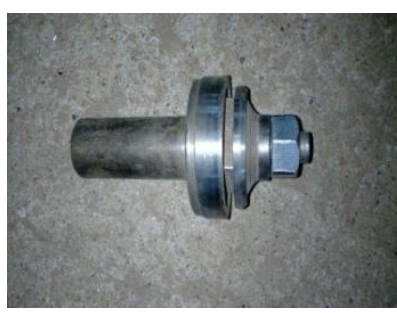

Fig.1 fixture for liner plate

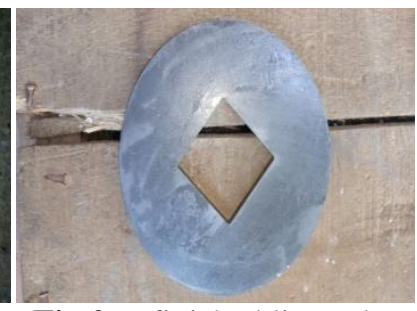

Fig.2 unfinished liner plate

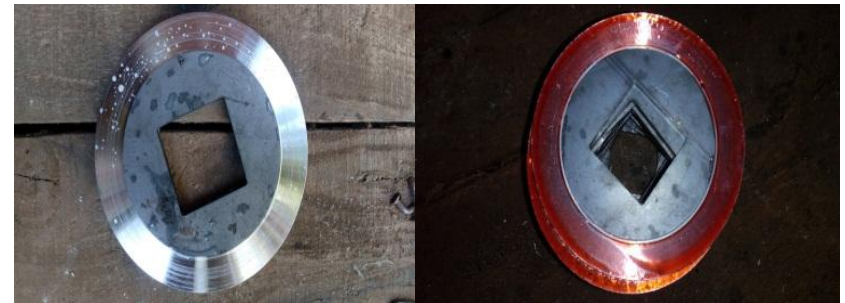

Fig.3 liner plate finished on $\mathrm{CNC}$ anobond binder

After application of lining material on place where binder is applied, to remove extra lining material the liner plate is loaded on lathe where it is mounted on fixture shown above. 2 single point cutting tools are used to finish 2 different sides of liner plate as shown below. 


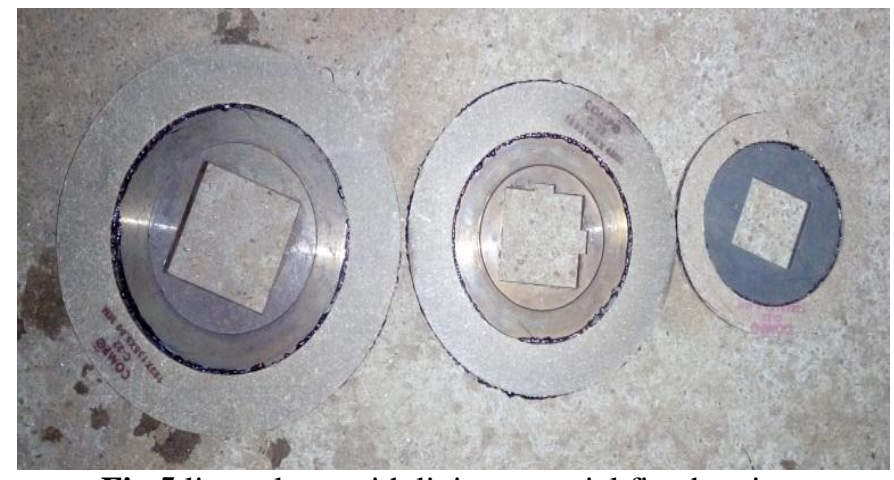

Fig.5 liner plates with lining material fixed on it

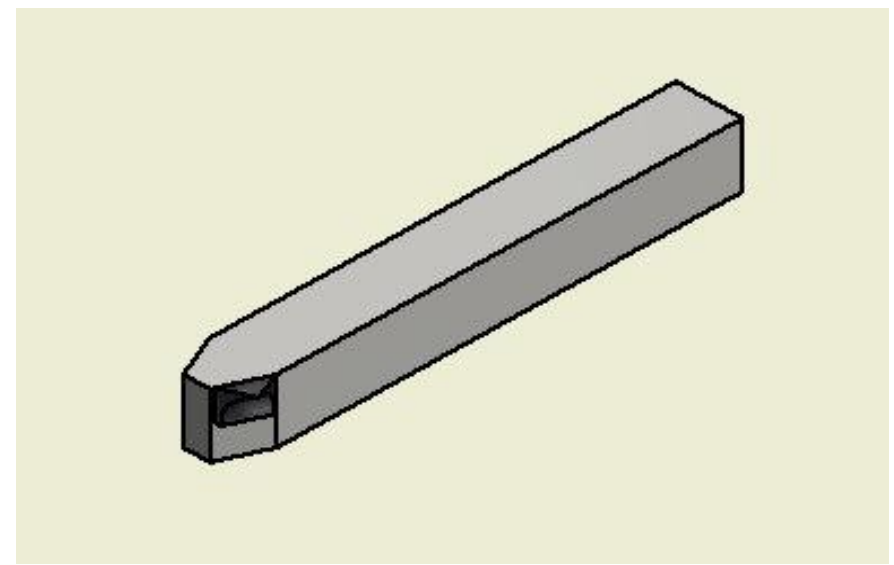

Fig.6 single point cutting tool

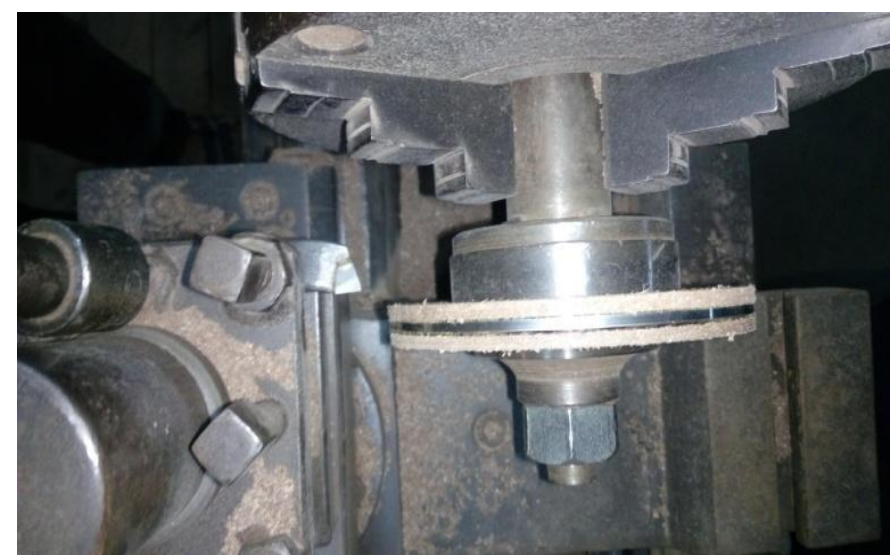

Fig.7 tool to finish left hand side

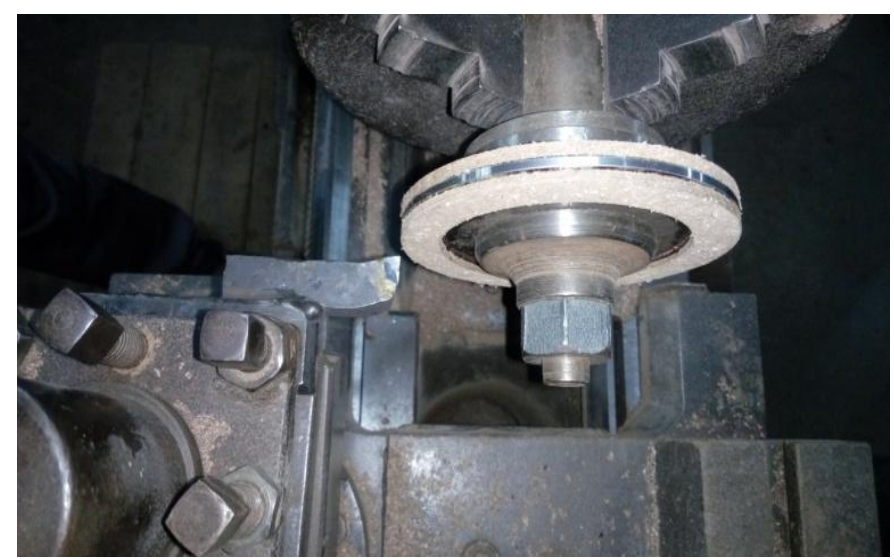

Fig.8 tool to finish right hand side
Time study for total processing time of $115 \mathrm{~mm}$ liner plate is recorded as;

Table.1 Time study for $115 \mathrm{~mm}$ liner plate diameter

\begin{tabular}{|c|l|c|c|c|}
\hline $\begin{array}{c}\text { Sr. } \\
\text { No }\end{array}$ & Operations & $\begin{array}{c}\text { Reading- } \\
\mathbf{1} \\
\text { (sec) }\end{array}$ & $\begin{array}{c}\text { Reading- } \\
\mathbf{2} \\
\text { (sec) }\end{array}$ & $\begin{array}{c}\text { Reading3 } \\
\text { (sec) }\end{array}$ \\
\hline $\mathbf{1 .}$ & $\begin{array}{l}\text { Work-piece } \\
\text { loading }\end{array}$ & 13 & 16 & 12 \\
\hline 2. & Turning & $22+18$ & $20+20$ & $23+19$ \\
\hline 3. & $\begin{array}{l}\text { Machining } \\
\text { R.H.S }\end{array}$ & $28+21$ & $33+18$ & $31+19$ \\
\hline 4. & $\begin{array}{l}\text { Machining } \\
\text { L.H.S }\end{array}$ & $32+19$ & $29+21$ & $31+22$ \\
\hline 5. & Finishing & 9 & 8 & 10 \\
\hline 6. & Inspection & 12 & 13 & 10 \\
\hline 7. & Unloading & 7 & 8 & 8 \\
\hline
\end{tabular}

Liner plates are made up of mild steel which has contains

$\checkmark$ Carbon-0.16-0.18\% (max of $0.25 \%$ is allowable)

$\checkmark$ Manganese- 0.70-0.90\%

$\checkmark$ Silicon- $0.40 \%$ (max)

$\checkmark$ Sulfur- $0.04 \%$ (max)

$\checkmark$ Phosphorous- 0.04\% (max)

Mild steel has properties like;

$\checkmark$ Modulus of elasticity for industry grade mild steel= $210,000 \mathrm{MPa}$

$\checkmark$ Density $=7860 \mathrm{Kg} / \mathrm{m}^{3}$

$\checkmark \quad$ It is good conductor of electricity

$\checkmark \quad$ It has good malleability and ferromagnetic properties

$\checkmark$ Because of carbon content it is very much prone to rust

There are 2 different parts of tool one is called "flank" and other is tip or tooth of tool.

Flank -It is fitted in tool post. It is made up of Iron which has following properties,

$\checkmark \quad$ Thermal Expansion- $11.8 \mu \mathrm{m} /(\mathrm{m}-\mathrm{k})$ at $25^{\circ} \mathrm{C}$

$\checkmark$ Thermal Conductivity- $80.4 \mathrm{~W} /(\mathrm{m}-\mathrm{k})$

$\checkmark$ Young's Modulus- $211 \mathrm{GPa}$

$\checkmark$ Shear Modulus- 82GPa

$\checkmark$ Poisson's ratio- 0.29

$\checkmark$ Brinell Hardness- 200-1180 MPa

Tip or Tooth- It is actually used for removal of material and is made up of Cemented carbide whose characteristics are,

$\checkmark$ Gives good surface finish

$\checkmark \quad$ Allows faster machining than H.S.S and other tools

$\checkmark \quad$ Can withstand higher temperature (up to 348k) at tool w/p interface than H.S.S

$\checkmark \quad$ Can work efficiently at higher cutting speed.

\section{PROPOSED PROCESSING}

In proposed processing 2 carbide tips are brazed on single on flank which eliminates tool changing time and results in reduced process time. Proposed tool is as shown below, 


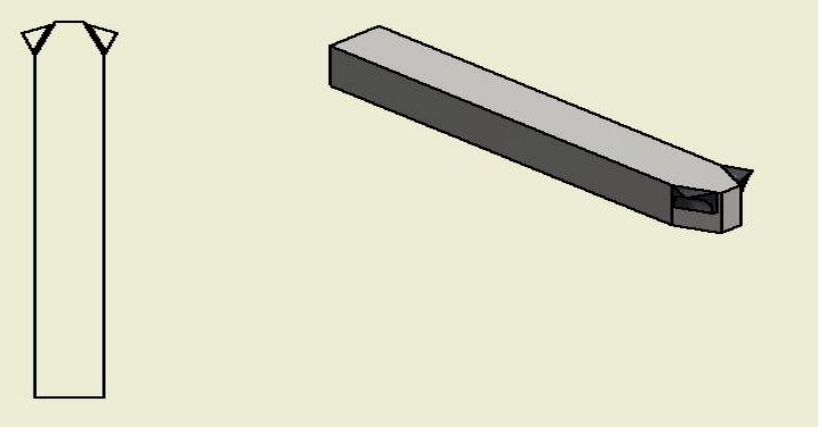

Fig.9 proposed tool

This tool has similar properties as that of existing tools. Using this tool processing time is recorded for processing of $115 \mathrm{~mm}$ diameter liner plate which is as shown in table below.

Table-4 Time study for $115 \mathrm{~mm}$ liner plate diameter

\begin{tabular}{|c|l|c|c|c|}
\hline $\begin{array}{c}\text { Sr. } \\
\text { No }\end{array}$ & Operation & Reading-1 & Reading-2 & Reading-3 \\
\hline $\mathbf{1}$ & $\begin{array}{l}\text { W/P } \\
\text { Loading }\end{array}$ & 12 & 10 & 10 \\
\hline $\mathbf{2}$ & Turning & 30 & 30 & 28 \\
\hline $\mathbf{3}$ & Facing R.H.s & 27 & 30 & 25 \\
\hline $\mathbf{4}$ & $\begin{array}{l}\text { Facing } \\
\text { L.H.S }\end{array}$ & 30 & 26 & 22 \\
\hline $\mathbf{5}$ & Finishing & 7 & 7 & 6 \\
\hline $\mathbf{6}$ & Inspection & 10 & 9 & 12 \\
\hline $\mathbf{7}$ & Unloading & 8 & 6 & 6 \\
\hline
\end{tabular}

\section{COMPARISON AND ANALYSIS}

Table-5 Comparative Time analysis

\begin{tabular}{|c|l|c|c|}
\hline Sr.No & $\begin{array}{l}\text { Average time } \\
\text { taken }\end{array}$ & $\begin{array}{l}\text { For existing } \\
\text { tool(sec) }\end{array}$ & $\begin{array}{c}\text { For proposed } \\
\text { tool }(\mathrm{sec})\end{array}$ \\
\hline $\mathbf{1}$ & For Loading & 12 & 11 \\
\hline $\mathbf{2}$ & For Turning & 40 & 30 \\
\hline $\mathbf{3}$ & $\begin{array}{l}\text { For Machining } \\
\text { LHS }\end{array}$ & 50 & 28 \\
\hline $\mathbf{4}$ & $\begin{array}{l}\text { For Machining } \\
\text { RHS }\end{array}$ & 51 & 26 \\
\hline $\mathbf{5}$ & For Finishing & 9 & 7 \\
\hline $\mathbf{6}$ & For Inspection & 12 & 11 \\
\hline $\mathbf{7}$ & For Unloading & 8 & 7 \\
\hline $\mathbf{8}$ & Total & 182 & 120 \\
\hline
\end{tabular}

\subsection{Cost Estimation}

\subsubsection{For Existing Processing}

Cost of Flank $(8-10 \mathrm{~cm}$ in length $)=$ Rs.30/-

Cost of Carbide Tip $=$ Rs.70/-

Cost of brazing single tip $=$ Rs.70/-

Total Cost $=2$ Cost of (flank + tip + brazing $)$ (for 2 tools)

$$
\begin{aligned}
& =2(30+70+70) \\
& =\text { Rs.340/- }
\end{aligned}
$$

\subsubsection{For Proposed Processing}

Cost of Flank $=$ Rs.30/-

Cost of carbide Tip $=$ Rs70/-

Cost of Brazing $=$ Rs.70/-

Total Cost $=$ Flank cost $+2($ Tip cost + Brazing cost $)$

$=30+2(70+70)$

$=$ Rs.310/-

\subsection{Total Production Per Day}

\subsubsection{For Existing Tool}

Total production time allotted per day $=7 \mathrm{hrs}=25200 \mathrm{sec}$

Total time required for finishing 1 liner plate $=182 \mathrm{sec}$

Total number of liner plate finished $=(25200 / 182)$

$$
=139 \text { pieces }
$$

Rate of Production $=$ Total number of products finished $/$ Total working time in hour

$$
\begin{aligned}
& =139 / 7 \\
& =20 \text { pieces per hour }
\end{aligned}
$$

\subsubsection{For Proposed Tool}

Total production time allotted per day $=7 \mathrm{hrs}=25200 \mathrm{sec}$ Total time required for finishing 1 liner plate $=120 \mathrm{sec}$ Total number of liner plate finished $=7 *(3600 / 120)$

$$
=210 \text { pieces }
$$

Rate of Production $=$ Total number of products finished $/$ Total working time in hour

$$
\begin{aligned}
& =210 / 7 \\
& =30 \text { pieces per hour }
\end{aligned}
$$

\subsection{Tool Life}

Number of work pieces finished between 2 successive regrinding of tip of tool is called as life of tool. Tool life in this case is totally depend upon
$\checkmark$ Cutting speed
$\checkmark$ Feed rate
$\checkmark$ Tip wear

Wear is not uniform throughout the life of tool. The wear is initially rapid, then settles down at uniform rate and finally accelerates at very high rate till failure of tip occurs.

Calculated tool life is;

$\checkmark \quad$ For Existing tooling system-55-60pieces

$\checkmark$ For proposed tooling system- 55-60pieces

\subsection{Cutting Temperature}

Mean temperature along tool face is called as cutting temperature. Cutting temperature is not constant through the tool, chip \& work-piece.This temperature is measured directly by means of different thermocouple techniques.

Cutting temperature is either;

1. Measured in the real machining process, or

2. Predicted in machining process design 
The maximum temperature is developed not on the very cutting edge, but at tool rake some distance away from the cutting edge. There is no simple formula to measure the temperature field. Therefore, predictive approaches must be relied on to obtain the mean cutting temperature and the temperature field in the chip, tool and the work-piece.

Calculated cutting temperature is;

$\checkmark$ For Existing tooling system- $32^{\circ} \mathrm{C}$ to $34^{\circ} \mathrm{C}$

$\checkmark$ For proposed tooling system- $32^{\circ} \mathrm{C}$ to $40^{\circ} \mathrm{C}$

This $40^{\circ} \mathrm{C}$ i.e $313 \mathrm{~K}$ is less than $348 \mathrm{~K}$ (max sustainable temperature of cemented carbide), hence tool tip is safe.

\section{CONCLUSION}

By applying proposed processing system results obtained are;

$\checkmark$ Time required for finishing one brake liner plate is been reduced to $66.67 \%$

$\checkmark$ Rate of production per hour has been increased up to $150 \%$

$\checkmark \quad$ Tooling cost has been reduced to $90 \%$

$\checkmark$ Average tool life is same as that for existing tooling system

$\checkmark$ Cutting temperature is increased but it doesn't affect rate of production or life of tool.

Content below gives an overall idea regarding improvement in brake liner processing with respect to tooling cost, processing time and rate of production and other factors.

Table 6 Overall Process Comparison

\begin{tabular}{|c|l|c|c|}
\hline $\begin{array}{c}\text { Sr. } \\
\text { No }\end{array}$ & \multicolumn{1}{|c|}{ Parameters } & $\begin{array}{c}\text { Existing } \\
\text { System }\end{array}$ & $\begin{array}{c}\text { Proposed } \\
\text { System }\end{array}$ \\
\hline $\mathbf{1}$ & Tooling Cost & $340 /-$ & $310 /-$ \\
\hline $\mathbf{2}$ & $\begin{array}{l}\text { Processing time per } \\
\text { piece(sec) }\end{array}$ & 182 & 120 \\
\hline $\mathbf{3}$ & $\begin{array}{l}\text { Rate of production } \\
\text { (pieces / shift) }\end{array}$ & 140 & 210 \\
\hline $\mathbf{4}$ & Tool life (pieces) & $50-60$ & $50-60$ \\
\hline $\mathbf{5}$ & $\begin{array}{l}\text { Cutting tool } \\
\text { temperature }\end{array}$ & $32^{\circ} \mathrm{C}$ to $34^{\circ} \mathrm{C}$ & $32^{\circ} \mathrm{C}$ to $40^{\circ} \mathrm{C}$ \\
\hline
\end{tabular}

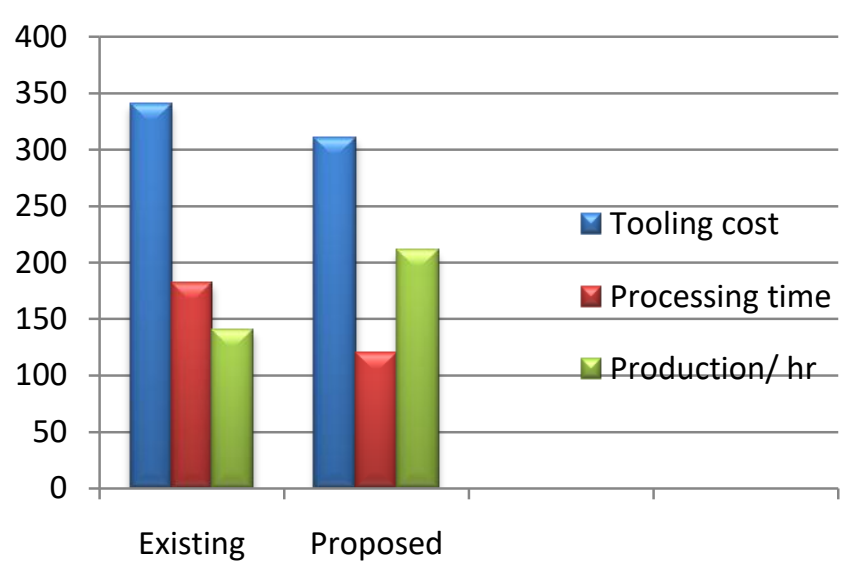

Graph-3 Overall Process Comparison

\section{REFERENCES}

[1] Duong Xuan-Troung and Tran Minch-Duc, Effect of Cutting Condition on Tool Wear and Surface Roughness during machining, IJMTM-2014.

[2] M.Narsimha, K.Shridhar, Improving Cutting Tool Life,IJERD-Volume 7, May 2013.

[3] M.G RathiAnd S.V Kadam,Review of different approaches to Improve Tool Life, IJIRSET-Volume 3, April 2014.

[4] PriyankaBankar And S.N.Khan, Paper on Composite Brake Friction Lining for Lining applications on Band Brake, Volume 2, November 2014.

[5] Dr. R.UmamaheswarRao, Paper on Alternate Materials for Asbestos Brake Pads and its characterization, Volume: 02, May-2015.

[6] K.K. Ikpambese, D.T. Gundu, L.T. Tuleun "Evaluation of palm kernel fibers (PKFs) for production of asbestos-free automotive brake pads" February 2014.

[7] Armarego, E. J. A., Verezub, S., Samaranayake, P., The effect of coatings on the cutting process, friction, forces and predictive cutting models in machining operations, Proceedings of the Institution of Mechanical Engineers, Part B:Journal of Engineering Manufacture 216 (2002) 347-356.

[8] ISO, ISO 3685 - Tool life testing with single point turning tools, 2nd Edition (1993).

[9] R.M. Sundaram and B.K. Iambert, Surface Roughness Variability of AISI 4140 Steel in Fine Turning Using Carbide Tools, International Journal Production, 17 (3) (1979) 249-258. 